\title{
Innovative digital design delivery for the Ordsall Chord in Manchester, UK
}

1 Brian Duguid BEng, FICE Practice Leader Bridges, Mott MacDonald, Altrincham, UK

2 Jason Hyde BEng, MSC, CEng, MICE Chartered Civil Engineer, Mott MacDonald, Altrincham, UK (corresponding author: jason.hyde@mottmac.com)
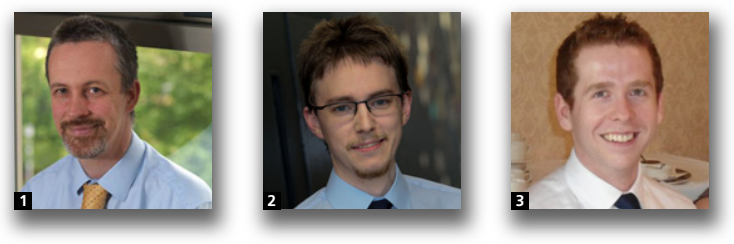

3 Howard Pullan MEng, CEng, MICE Senior Engineer, Aecom, Altrincham, UK

The Ordsall Chord rail link project in Manchester, UK was designed using building information modelling. Federated three-dimensional models produced by all design disciplines were held in a common data environment, with modelling developed down to the level of individual reinforcement bars. Early involvement of both the main contractor and its steel fabrication subcontractor allowed conventional roles and processes to be challenged. The design models and drawings were produced on the designer's behalf by the steelwork subcontractor, although these models and drawings were still owned by the structural designer. In some cases, drawings were dispensed with entirely, and key structures were built directly from the digital model, prepared in collaboration between fabricator and designer, and taking advantage of the fabricator's highly automated working method. This paper explains the contractual arrangements and collaborative behaviours that allowed conventional roles to be challenged, and discusses the efficiencies that resulted.

\section{Introduction}

\subsection{The Ordsall Chord}

UK railway operator Network Rail's multi-billion-pound great north rail programme (incorporating various projects including Northern Hub, North West Electrification and Trans-Pennine Route Upgrade) was an ambitious attempt to transform rail connectivity in the north of England, delivering hundreds more trains to run each day and providing space for millions more passengers a year (Wynne, 2013). The Ordsall Chord project is a key part of the programme (Network Rail, 2016).

The Ordsall Chord for the first time directly links all five of Manchester's city centre railway stations: Piccadilly, Oxford Road, Deansgate, Salford Central and Victoria (see Figure 1). Opened at the end of 2017, it created improved north-south rail connectivity, removed conflicting operational moves to the south of Piccadilly station, and allowed a number of new direct rail services to be introduced.

To achieve this, a short length of the chord was supported on a new viaduct, and the existing Victorian brick arch railway viaducts that it connected were extensively altered over a large part of their length (see Figure 2).
In total, $3 \cdot 2 \mathrm{~km}$ of existing railway track, almost entirely supported on viaduct, was altered. New structures were built to accommodate $350 \mathrm{~m}$ of new track, and a further $345 \mathrm{~m}$ of existing viaduct was widened (Duguid and Whiteaker, 2017).

\subsection{New and modified bridges}

The existing railway viaducts were widened in reinforced concrete arch construction. A number of existing flat spans were replaced with new, wider structures as part of this work, including new reinforced concrete beam and steel filler beam spans.

Two new single-span half-through steel railway underbridges were built across Water Street to accommodate the southern junction of the Ordsall Chord. Where the new railway line passes over the existing Trinity Way dual carriageway, a continuous three-span half-through girder bridge was built.

The new railway is carried over the River Irwell on a steel network arch bridge. This is the first of its type in the UK, and the first asymmetric network arch bridge anywhere in the world (Bistolas et al., 2016; Duguid and Whiteaker, 2017).

Between these major spans, a number of short linking sections of viaduct were required, which were in reinforced concrete and filler beam construction (see Figures 3 and 4). 


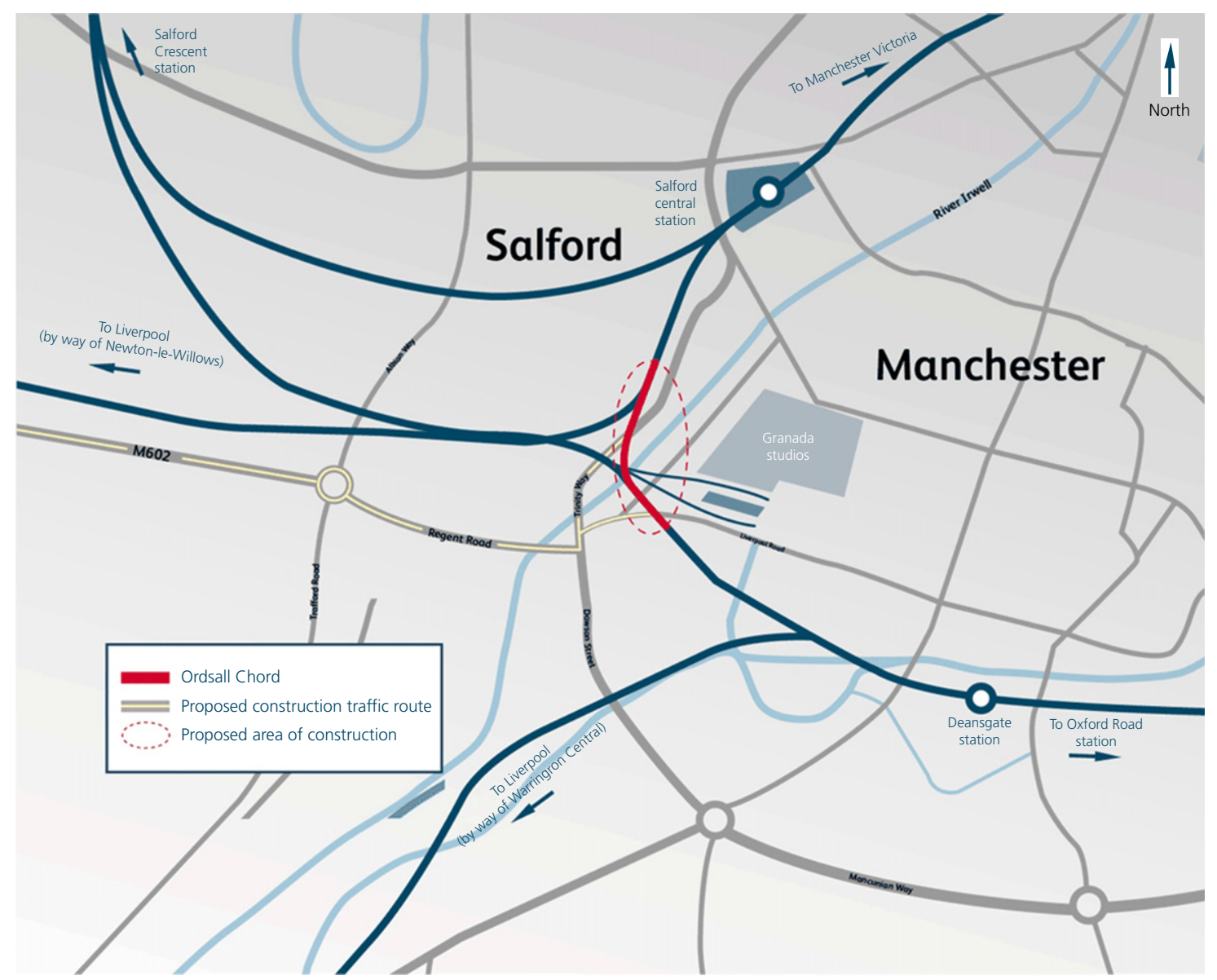

Figure 1. Map showing the location of the Ordsall Chord and the link that it provides between Manchester's railway stations

All the main steel bridges were built in weathering steel. The appearance of the steelwork on elevation is that of a continuous architectural 'ribbon', which extends beyond the main bridges onto a series of parapet and facade elements. One of the most geometrically challenging aspects of this 'ribbon' is the pair of non-structural 'cascade' facade elements, which sit between the network arch bridge and the adjacent bridge over Trinity Way and visually link the steelwork of both structures (see Figure 4).

The varying profile of the new and existing railway viaduct, variable plan curvature, width and skew, combine with the historic geometry of the existing infrastructure and the new architectural elements to establish extremely complex and demanding geometric relationships (Duguid et al., 2017a).

\subsection{Delivery partners}

To deliver the Ordsall Chord, the Northern Hub Alliance was formed, with Network Rail as the owner participant with Siemens, Amey-Sersa and Skanska-Bam joint ventures as the non-owner participants. The alliance operates on a no-dispute, shared risk basis, intended to encourage early involvement of key partners and flexibility in work allocation (see Figure 5).

The civil engineering participant, Skanska-Bam, appointed its design team, Aecom-Mott MacDonald joint venture (AMM JV), at tender stage, and the combined team worked closely together throughout design development.

It was recognised that certain aspects of the civil engineering works were particularly critical to the delivery programme, and the key steelwork subcontractor, Severfield, was engaged very early. As with the main civils contractor, the steelwork subcontractor's tender was evaluated with a large weighting given to the display of collaborative behaviours. During workshops conducted as part of the tender stage, both the contractor and subcontractor demonstrated a willingness and capacity to challenge conventional working methods and responsibilities. This proved invaluable in allowing innovative approaches to be 


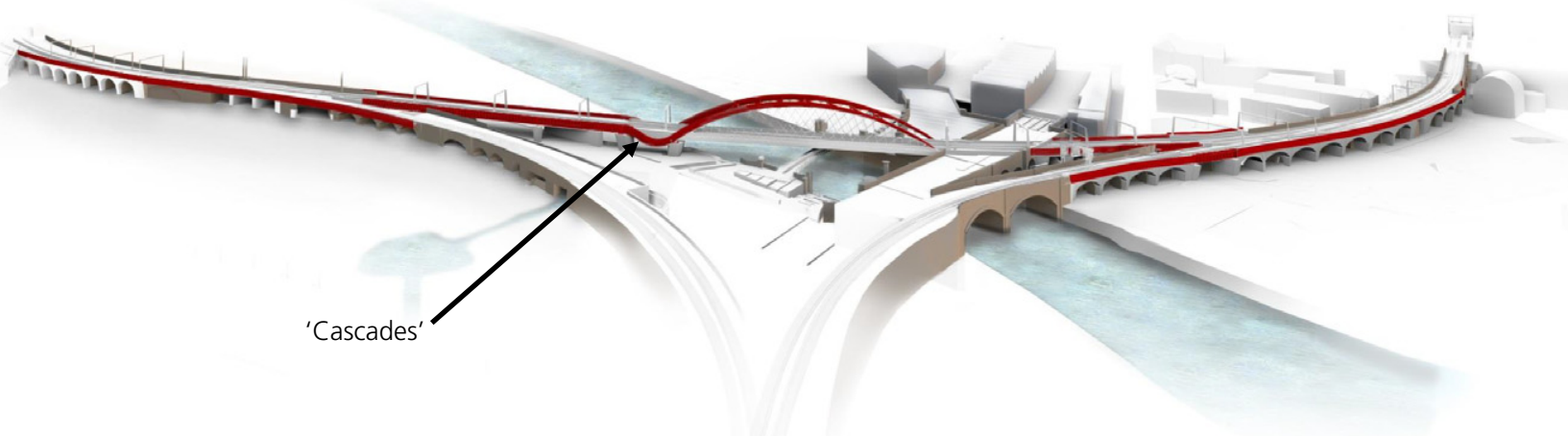

Figure 2. Architectural render of the completed Ordsall Chord

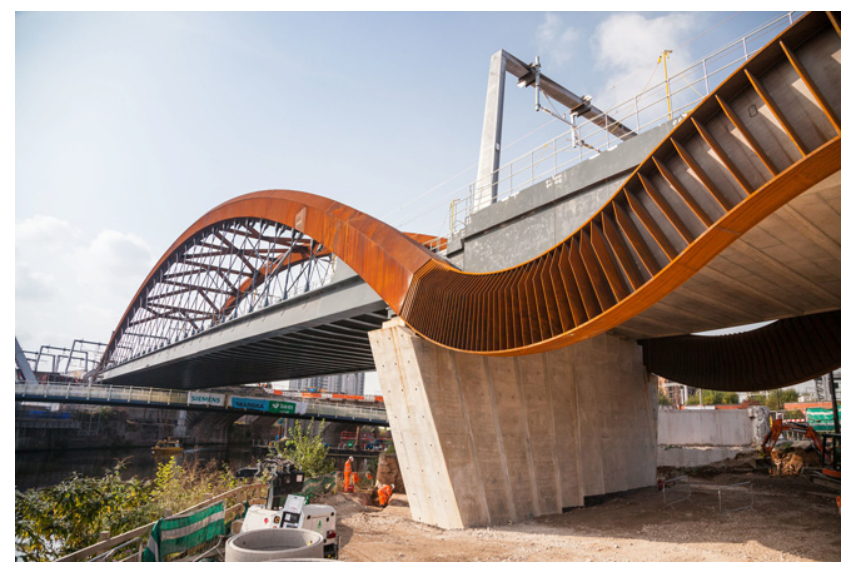

Figure 3. Photograph of Ordsall Chord from new urban realm development highlighting the North Bank Structure, which links the River Irwell Bridge (left) to the Trinity Way Bridge (right); image (c) Matthew Nichol Photography

adopted for the project's building information modelling (BIM) requirements.

\section{BIM level 2 implementation and delivery}

2.1 BIM aspirations and requirements

As the owner participant ultimately responsible for operation and maintenance of the new and existing infrastructure, Network Rail has recognised the role of digital technology in improving asset management capability. Its Orbis programme

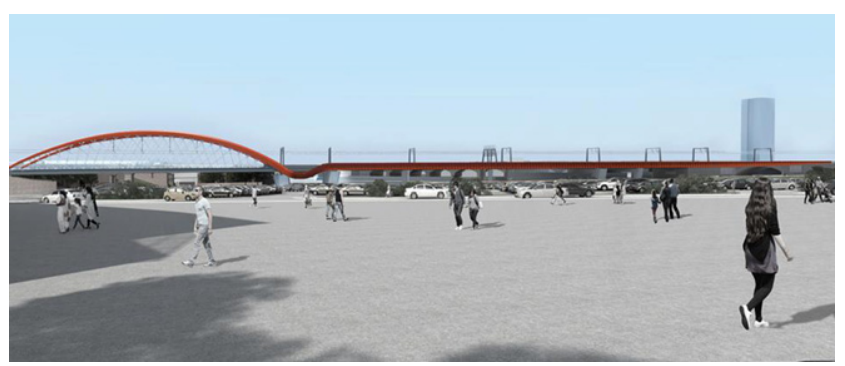

Figure 4. Eastern elevation of Ordsall Chord highlighting the architectural 'ribbon'

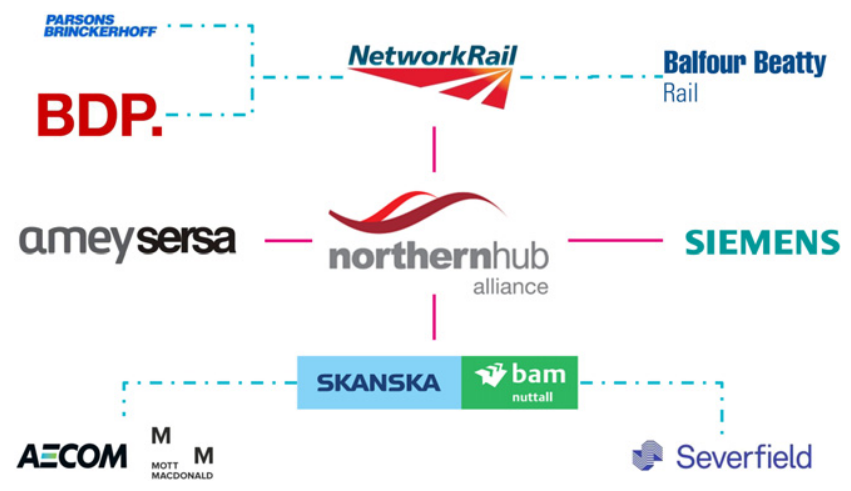

Figure 5. Northern Hub Alliance organisation and principal subcontractors 
(an acronym for 'offering rail better information services') is intended to bring asset information into the digital environment in an integrated manner, and a key element in this is to ensure that higher quality digital asset information is provided as an output of infrastructure enhancement projects (Anon, 2014).

For the Northern Hub Programme, Network Rail committed to an aspiration to deliver all key works across all disciplines using BIM, and to achieve BIM level 2 compliance by 2016 (BIM Industry Working Group, 2011). As well as providing better asset data, its intention was to improve interdisciplinary design coordination, and seek efficiencies during the design and construction phase.

For all Northern Hub schemes, Network Rail established consistent BIM and computer-aided design (CAD) standards to ensure that design and eventual asset data were provided in a consistent manner in a coordinated, federated model (a single complete model of the scheme formed as an aggregate of smaller models depicting discrete elements), accessed within a common data environment (CDE). The CDE, a Bentley Projectwise system, was provided by Network Rail for the use of all participants, including entities at any point in the supply chain. The data structure and workflow system was compliant with the requirements of BS 1192 (BSI, 2007). Bentley Microstation was designated as the software platform for provision of the federated model.

\subsection{Development of the BIM data}

Prior to the formation of the alliance, the outline design was developed as a single cross-disciplinary three-dimensional model in Microstation, relying on a range of survey information for existing railway systems and structures, with a mixture of topographical survey, three-dimensional laser scanning and information interpreted from conventional drawings (Stacy and Birbeck, 2013). These surveys were incomplete, and in particular did not include any intrusive survey to establish internal details of existing structures.

The primary design output at the outline design stage was in the form of conventional drawings, which were partly produced from the three-dimensional model and partly prepared by conventional methods. In addition, the architect had developed separate models to allow visualisations and other information to be provided. This approach was sufficient to allow considerable interdisciplinary design coordination (IDC) to be completed successfully, as well as preparation of the necessary drawings for technical approval and third-party consents submissions.

Following the appointment of the design-and-build civil engineering contractor, a range of additional survey works was undertaken to allow the development of a more accurate threedimensional model. Particular consideration was given to details of the existing structures, where new bridges would have to be constructed in close contact and with little tolerance for error.

The railway systems design was developed in Microstation using a number of specialist supporting packages. For the civil engineering work, the design team selected Bentley Aecosim as the core platform for modelling all existing and new structures. Aecosim is an architectural and structural engineering extension to Microstation, offering capabilities in modelling solid structural elements and in extracting information from models for the final construction drawings.

This approach was compliant with the project BIM and CAD standards, and has achieved successful compliance with BIM level 2 adopting normal multi-disciplinary roles and responsibilities.

\subsection{Aspirations for modelling and construction of steel bridges}

The design team looked to exceed Network Rail's requirements and seek additional efficiencies in the generation of design deliverables and the delivery of information to the construction team. It was recognised that the core technology platform adopted did not lend itself to the level of detail typically required by fabricators and others in the civil engineering supply. For example, the steelwork subcontractor would require information on every nut, bolt and weld, and normally would receive a completed set of drawings from the design team (possibly produced from a designer's three-dimensional model). From these, they would develop their own threedimensional fabrication model using specialist software capable of including all the necessary structural elements more accurately, and in a manner better suited to production of workshop information for plate cutting, including control of automated fabrication machinery.

It was also considered that the highly complex geometry of certain key steel structures would be impractical to model in detail within the federated design model.

The design team therefore recognised that a different approach was required to ensure that the architectural, engineering design and construction issues were properly coordinated, and that taking a new direction could also be used to facilitate improved integration with the steelwork fabricator's working processes.

\subsection{Interdisciplinary check procedure}

In accordance with the alliance engineering management plan, prior to each staged issue of a design deliverable, each 
discipline submitted the design model for review during an IDC meeting. The alliance BIM manager was then responsible for populating an empty container model with the submitted design models from each discipline, such that clashes and noncompliances could be identified and resolved during a meeting with representatives of all engineering disciplines.

Models to be submitted for IDC meetings were progressed to an appropriate checking status in accordance with the BS 1192 workflow (see Figure 9). This status was actively assigned by design teams within the CDE, and acted as a record that the various discipline models had been subject to an appropriate level of checking prior to being shared with others.

With no clear industry guidance on how to check a BIM model in this environment, the design teams extended the traditional checking methods used for drawings to include the models. With the ability to produce section cuts at any point in a model, the designers and checkers confirmed geometry, offsets, the position of an object in relation to the rest of the project (spatial coordination) as well as information relating to the make-up of a particular asset (and more discipline-specific details). Once this information had been confirmed as checked, the model was advanced through the workflow within the CDE by the responsible member of the team and submitted for IDC.

\section{Steel design modelling and drawings}

\subsection{Selection of Tekla Structures}

To address the challenges outlined in Section 2.3, the design team selected Trimble's Tekla Structures package to create the detailed steelwork design models. The package was judged to be the most suitable for creating models of the level of detail required. This would allow weld information, shear stud layouts and details of every nut and bolt to be modelled and depicted consistently on the design drawings. In addition, the architect-driven geometry of much of the steelwork resulted in a number of complex box girder and plate girder elements, particularly stiffeners, which would have been difficult to model accurately any other way (see Figure 3). Tekla Structures is the modelling platform used by Severfield (and many other steel fabricators) to drive their production processes, and the design team considered that if it was capable of accurate modelling for manufacture, it should also satisfy the designer's requirements.

This decision created an opportunity for the conventional modelling and drawing approach to be challenged, with the aim of achieving programme efficiencies and reducing error. The current norm in bridge construction in the UK is for the designer to develop conventional steelwork arrangement and detail drawings from a mixture of two-dimensional and three-dimensional modelling, and for the fabricator then to prepare their own three-dimensional fabrication model from scratch, using the designer's outputs.

Adoption of the fabricator's software platform (Tekla) allowed a different approach to be adopted. Severfield's BIM technicians, who were experienced in preparing models for fabrication, were embedded within the Aecom-Mott MacDonald engineering design teams. These technicians were responsible for producing three-dimensional models of the structural steelwork using Tekla Structures, and using these models to generate the conventional design drawings. These drawings communicated the design intent, enabled technical approval to take place and formed part of the records required for future asset management. Following substantial completion of the steelwork design drawings, the same technicians then returned to Severfield to further develop the BIM models to the final level required for the steelwork fabrication process.

Essentially, the fabricator's technicians operated as a specialised CAD resource for the structural designer, who remained entirely responsible for the engineering content of the model and drawings. Using this arrangement meant that the risks associated with producing the models were allocated to the party best able to manage them. It also improved continuity between the design and fabrication teams, and allowed AMM JV and Severfield to realise several key advantages.

\subsection{Steelwork modelling collaboration}

At the outset of the Ordsall Chord project, many of the engineering design teams had limited practical experience of threedimensional modelling in BIM. Although BIM is common in building works, it has penetrated the civil engineering and transport infrastructure markets more slowly, and the software platforms available are currently less mature.

By drawing on the experience of Severfield's detailers - both in terms of knowledge of the fabrication process and use of Tekla - steelwork models could be generated more efficiently than might otherwise have been possible. Knowledge of Tekla Structures gained from the steelwork detailers was also put to use by engineering design teams later in the project, where detailing of geometrically complex reinforced concrete elements was carried out in full three dimensions using the same package (Duguid, 2015; Duguid et al., 2017b).

Severfield's detailers were also able to reuse assets from the steelwork design models when generating the fabrication models, therefore minimising rework. Although some remodelling to account for the fabrication process was, particularly for the more complex structures, unavoidable (see e.g. Section 5.4), the scale of reuse of modelled assets was significant and meant 
a direct path for information generated by the design team to be used by the fabricator and their automated fabrication processes.

For one of the simpler structures on the scheme, Severfield was able to further minimise remodelling through intelligent use of their computer-aided manufacture capabilities. The design Tekla model showed the final profile of the main girders rather than the 'weightless' precamber profile required by the platecutting machine. For this structure, rather than remodel these elements using Tekla to create a fabrication model, the additional precamber required to create the 'weightless' profile was programmed into the plate-cutting machine, which was then able to cut the correct profiles automatically.

One significant advantage in this collaborative arrangement was that upon their return to the fabricator, the detailers already had a depth of knowledge of the structure and the design intent, and good working relationships with the design team. When combined with a detailed knowledge of the designer's BIM model, this meant that the risk of error in transfer of design information to the fabrication model could be minimised, with any remaining issues resolved with the design team effectively, and thus the fabrication model was generated more efficiently.

\subsection{Trinity Way Bridge}

One example of where this collaboration worked effectively was in the design of Trinity Way Bridge (see Figure 6 for a photograph of the finished structure). Sited towards the north end of the main Ordsall Chord viaduct, this is a $105 \mathrm{~m}$ long, three-span, continuous, half-through weathering steel structure with a steel-concrete composite deck. Curved in plan, it carries the new railway over the Manchester inner ring road

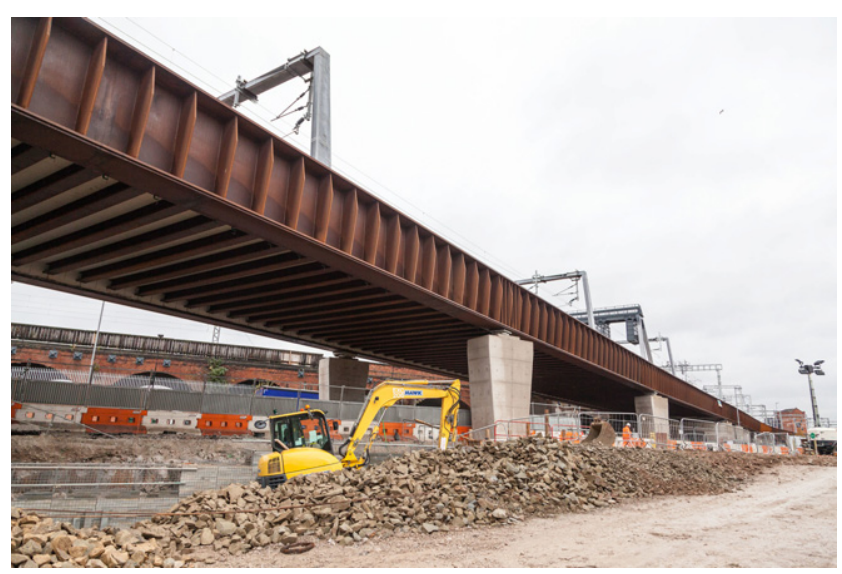

Figure 6. Trinity Way Bridge; image @ Matthew Nichol Photography

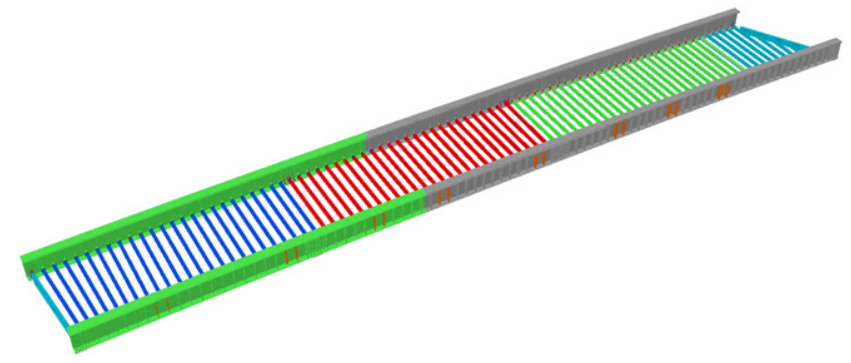

Figure 7. Trinity Way Bridge steelwork design model authored by the fabricator on the designer's behalf in Tekla Structures

(A6042 - Trinity Way) (see Figure 7 for the Tekla Structures model).

One of the challenges related to the design was the definition of the cross-girder geometry, and specifically the height of the cross-beam connections in relation to the main girders. Defining the level of these connections involved accommodating the combined effects of plan curvature of the deck, longitudinal fall of the bridge, precamber, uneven spans/varying skews, staged construction and tight constraints on headroom at the north-east corner of the deck. By having the fabricator's BIM technician involved in solving the associated geometric issues, the designer was able to ensure a good comprehension of the problem, thus helping to avoid issues and potential queries later in the modelling process.

Despite the geometric complexity of the design steelwork model, the detailer was able to retain a significant proportion of the design model for use within the fabrication model (e.g. all main girder transverse stiffeners, all cross-beams and associated connections - see Figure 8). This process was assisted by the fact that, as the same detailer built both models he was able to determine directly which elements of the design model could be retained and which required amendment.

\subsection{Verification of Tekla Structures design model} With the introduction of another modelling package in addition to Bentley Aecosim, one of the challenges for the engineering design teams was how to incorporate the Tekla model within the overall federated model.

Early in the design process, structural models were all prepared by the engineering design teams within Aecosim, with individual models all capable of being combined within a federated model, checked against each other, and verified through the IDC process. Following the fabricator's engagement as the steelwork detailer, Tekla Structures models of the steelwork of individual structures were developed from the original Aecosim geometry. These steelwork design models were then 


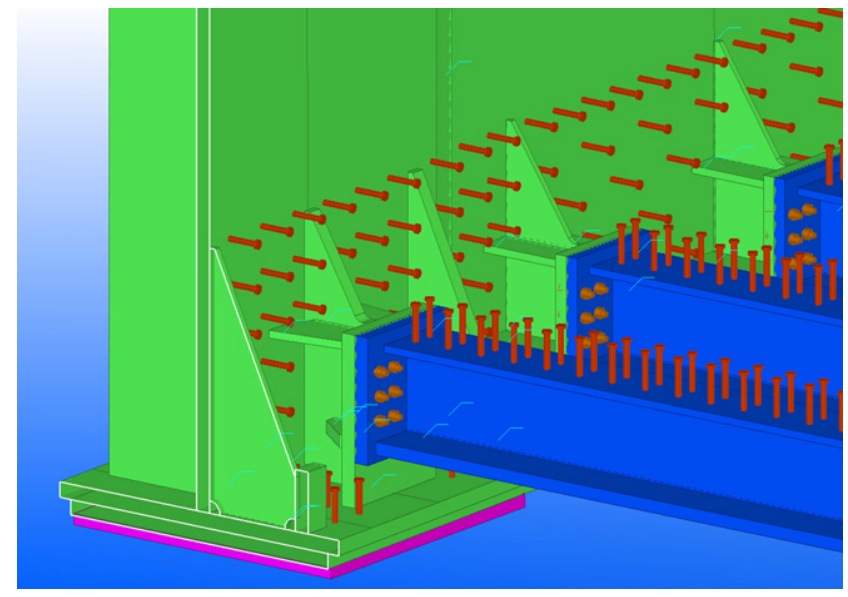

Figure 8. Elements of the Trinity Way Bridge steelwork design model, which were retained for the fabrication model, including cross-girders, connection details and main girder transverse stiffeners

verified by returning them into Aecosim and comparing them against the original design geometry. Following verification of the Tekla models by the designer, the original Aecosim steelwork model was discarded and replaced with the version created using Tekla. This revised Aecosim model, incorporating the steelwork design model, was the version used for all subsequent verification within the federated model.

The procedure for interchanging the models between software packages introduced a number of challenges. These were related to the fact that each package was unable to directly import a model from the other. Therefore, an intermediate file format had to be used that was able to be imported and exported by both pieces of software. The design team adopted the industry foundation classes (IFC) format for this purpose, this being a platform neutral file format designed for data exchange between compatible BIM modelling applications (Bentley, 2008). Although designed for the purpose of exchanging information, the design team found that this process could introduce errors and loss of functionality in the converted model when imported into the destination software.

For example, although the IFC conversion process worked effectively for standard catalogue items such as universal beam sections, the complex bespoke geometry of structures such as Trinity Way Bridge meant modelling with non-standard components. As a result, when converting from Aecosim to Tekla by way of IFC, this resulted in models that appeared visually correct, but could not be properly edited.

This 'double handling' of information and the loss of intelligence in the modelled elements through the conversion process meant taking another step away from the ideal of a single common steelwork model to be shared by the steelwork designer and fabricator, and led to additional work for the design team in verifying the models in both Tekla and Aecosim. This impact was experienced not just within the modelling of steelwork but also the modelling of concrete reinforcement within Tekla (see Figure 9 for an overview of the exchange of information between software packages).

The use of different versions of Tekla Structures by the designer and the fabricator also introduced issues. For Trinity Way Bridge for example, this manifested when determining holing of steel plates to accommodate reinforcement. Hole locations were determined within Tekla as part of the reinforced concrete detailing. Difficulties in importing plate holing information back into the original steelwork design model, which had been built in an earlier version of the software, led to a separate model being issued to the fabricator. The new model contained only plate holing information, which again detracted from the aim of maintaining a single steelwork model for that structure, and led to additional checking work for the design team.

Although the challenges described above meant that the project team was not able to realise all of the aims set at the beginning of the project related to the delivery of steelwork models, the approach did provide efficiencies and benefits to both collaborators. By providing time and cost savings in the steelwork modelling process, both the design and fabrication drawings could be produced and delivered more efficiently. Early engagement of the team led to a dramatic reduction in the number of design queries compared to experience elsewhere.

Crucially, this collaborative approach also laid the foundations for further innovation, and examining the possibility of full three-dimensional digital delivery on selected structures.

\section{4. $\quad$ River Irwell Footbridge - three-dimensional digital delivery}

The River Irwell Footbridge is a unique structure on the project. Although it was designed and constructed as part of the enabling works for the wider Ordsall Chord, the ownership and future operation and maintenance of the footbridge fall to the local authority (not Network Rail). This meant that the technical approval process followed the design manual for roads and bridges standard, BD 2/12, and the design was approved by the local authority (HA, 2012).

The design was developed within the common data environment (CDE) to allow geometry to be coordinated with adjacent structures and public realm works. However, the structure 


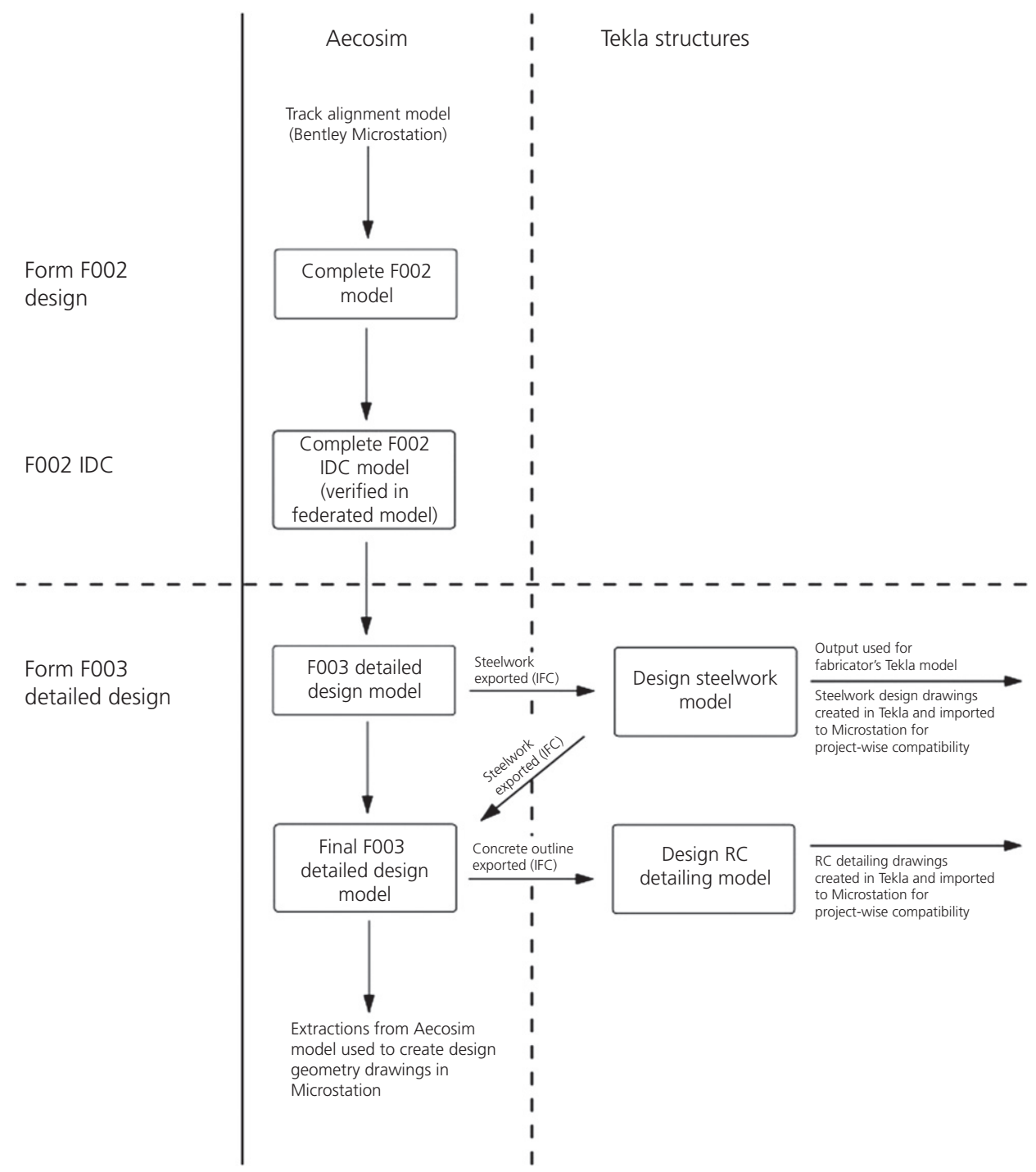

Figure 9. Diagram showing an overview of the exchange of information between models and software packages over the course of the design of Trinity Way Bridge

was subject to a different approval process, and the asset management records did not have to comply with Network Rail's arrangements for the rest of the project.

The unique situation for this structure, coupled with the collaborative relationship with the steelwork fabricator, allowed the design team to progress further with the adoption and application of BIM.

\subsection{Preliminary design model}

The River Irwell Footbridge is a single-span structure consisting of a central steel box girder with $2.8 \mathrm{~m}$ cantilevered walkways on both sides. The structure spans $49.5 \mathrm{~m}$ across the
River Irwell and has an overall width of $7 \cdot 0 \mathrm{~m}$. The steel box is pentagonal in cross-section and varies in depth from $1.1 \mathrm{~m}$ at its ends to $1.4 \mathrm{~m}$ at midspan (see Figure 10).

An initial model was created in Bentley Aecosim Building Designer in order to represent the proposal and ensure the correct setting within the urban realm design. As part of the project requirements, a three-dimensional model of the structure was developed. This included the principal structural members and plate sizes, but not connection details. The preliminary design model was constructed to facilitate the urban realm design surrounding the footbridge, and also for coordination checks with the new railway viaduct (e.g. vertical 


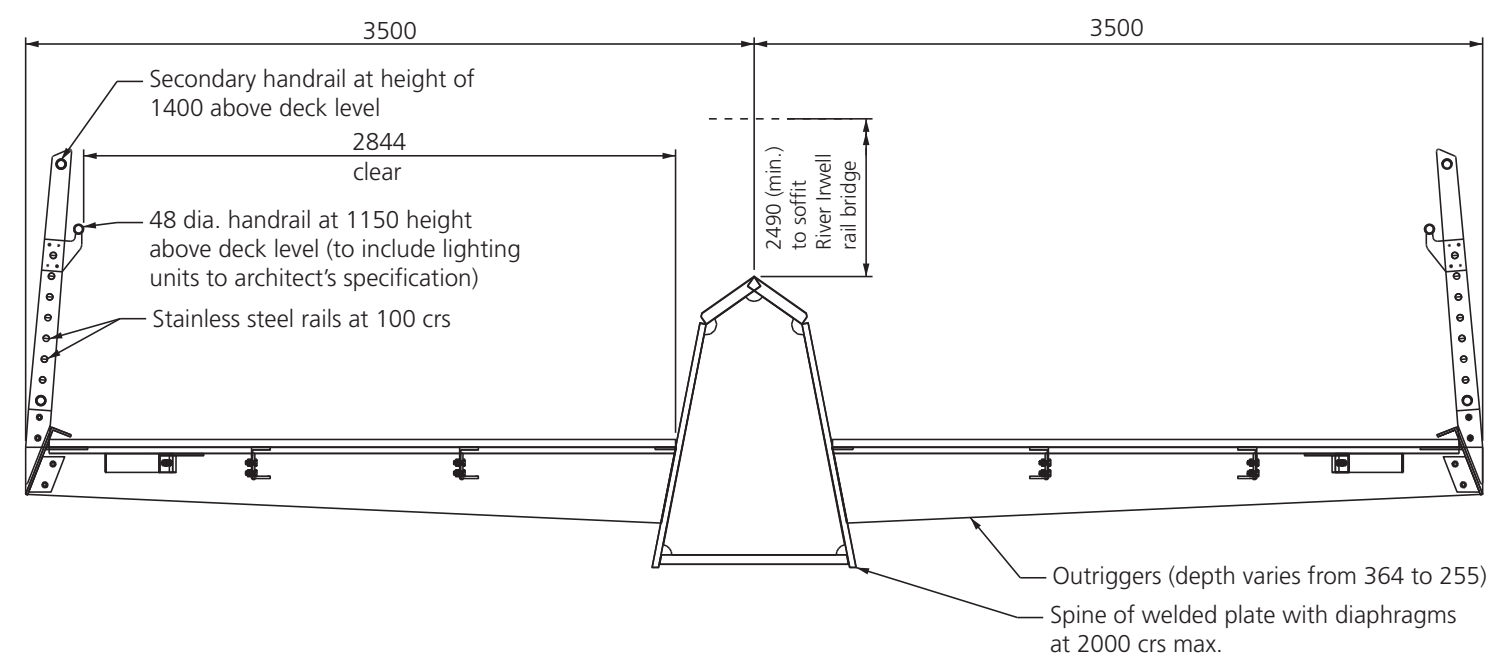

Figure 10. Cross-section of River Irwell Footbridge (dimensions in $\mathrm{mm}$ )

clearances to the underside of the new viaduct to safeguard against trespassing on the railway).

The Aecosim model was then transferred to Tekla Structures as a reference model using IFC file format for the detailed design stage.

\subsection{Detailed design model}

As discussed in Section 3, the detailed design model for the steel superstructure was prepared by the fabricator (using Tekla Structures) on behalf of the design team. As with other structures, the fabricator's detailer was co-located with the design team for the duration of the detailed design process, thus allowing the designer to capitalise on the experience of the fabricator, resolve potentially problematic details early in the design and also ensure that the model could be assembled with consideration for the fabrication process. This arrangement also allowed the detailer to gain a much greater appreciation of the reasons for the arrangement of specific details.

Owing to particular architectural requirements for the bolted connections and the orientation of the secondary bracing members, all of the individual connections were modelled, along with weld details for each of the steel plates, material classification and the various requirements for fabrication execution (see Figure 11).

Owing to the level of detail provided in the steelwork model, the design team quickly recognised that, although drawings are the traditional medium for communicating information to the fabrication and construction teams, all of the information required to fabricate the bridge was already contained within

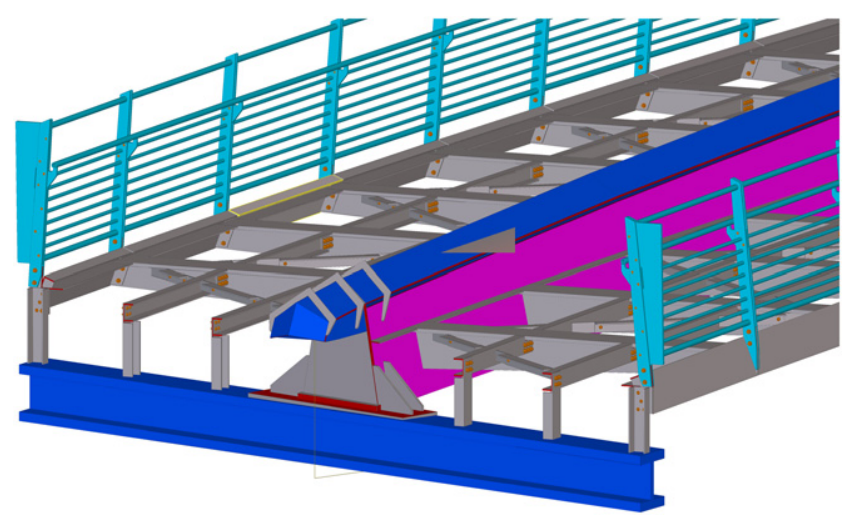

Figure 11. River Irwell Footbridge detailed design model

the model. When coupled with the additional level of knowledge gained by the fabrication team (due to the co-location and collaborative approach to the design), it was agreed that traditional steelwork design drawings were not required for the fabricator to construct the bridge.

This allowed the design and fabrication team to realise time and cost savings by omitting production of superfluous twodimensional drawings. The fabrication team also realised an estimated $50 \%$ time saving attributable to the transfer of knowledge and use of the design model when making the necessary adjustments for plate cutting and precamber requirements.

\subsection{Providing technical assurance}

The lack of traditional drawings did, however, present a challenge for the technical assurance process. It was not initially 
obvious how the design would be checked and certified, how the bridge owners would satisfy themselves as to its acceptability, or how they could be confident of having suitable information to facilitate future asset management.

Through consultation with the technical approval authority (TAA) throughout the design process, the design team agreed an amendment to the standard BD 2/12 design and check certificate such that it specifically covered the submission of a model instead of drawings.

Taking account of the various parties involved in approving the design and with the aim of approving and issuing only the three-dimensional model, the design team hosted a joint meeting with all interested parties in attendance (designer, checker, contractor, fabricator and TAA). The aim of this meeting was to mimic the traditional approval process of submitting a package of information for review and to respond to comments raised by each party. The meeting allowed all parties to interrogate the design information at its source, using a technician to operate the three-dimensional model on behalf of the attendees. It also allowed the ultimate approver (the TAA) to ask questions of the designer, checker and contractor to reassure themselves that all of the necessary design procedures had been followed.

Through this meeting, and by facilitating easy access to all the relevant information, the approval process (normally allocated 4 weeks in the programme) was reduced to one day. This was achievable as this method facilitated the TAA's rapid understanding of the design (by being in the room with the complete design and construction team).

\subsection{Fabrication process}

Owing to the level of involvement from the fabricator during the design process, a significant amount of knowledge that would typically be lost between design and construction stages of a project was successfully transferred. This gave the fabricator the confidence to adopt the detailed design model and amend it directly to account for the fabrication precamber. The fabricator was able to reuse over $75 \%$ of the detailed design model, resulting in an estimated time saving of approximately $50 \%$ when compared to the traditional method of building a fabrication model from a set of design drawings.

The fabricator was then able to use their own in-house techniques to 'digitally build' the bridge and set it out relative to the bay in the fabrication shop that would be used. This information was then fed to the shop team who used total stations to set the bridge components out and keep control of the tight tolerances during the build (see Figures 12 and 13).

\subsection{Stanley Street Bridge - repeating the process}

Stanley Street Bridge is a single-span filler beam deck which provides the connection between Trinity Way Bridge and the

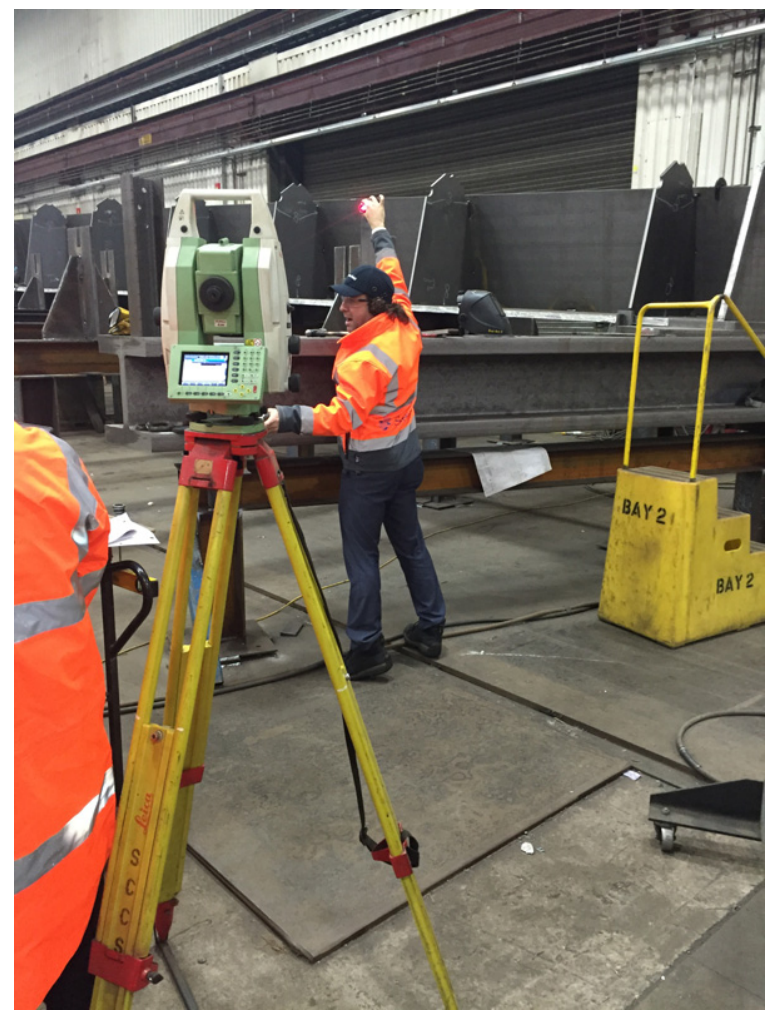

Figure 12. Use of three-dimensional model data to control the fabrication of the footbridge

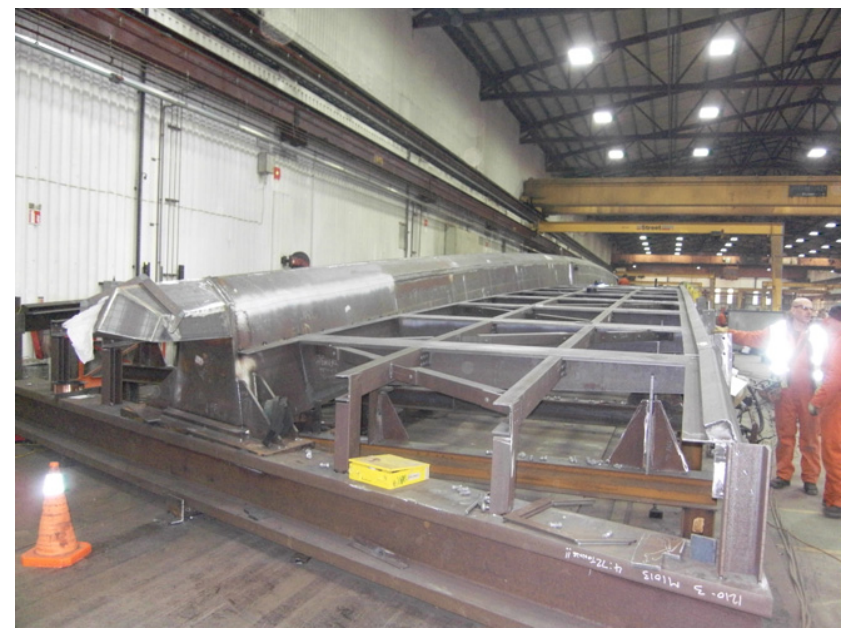

Figure 13. River Irwell Footbridge nearing completion of fabrication stage 
Middlewood Viaduct. The steel beams encased within the concrete deck span between $15.0 \mathrm{~m}$ and $15.5 \mathrm{~m}$ (varying due to the tapered geometry of the structure) and are $900 \mathrm{~mm}$ deep.

Again, the fabricator prepared the detailed steelwork design model for the designer, consisting of the embedded beams and associated cross-bracing. This model was then checked for both accuracy and coordination with the concrete reinforcement model (also modelled in Tekla Structures, but authored by the main designer's own staff). This provided confidence that the reinforcement could be successfully fixed through the large number of holes cut through the filler beam webs (see Figure 14).

To enhance the delivery of this structure for fabrication, the design team looked to the River Irwell Footbridge as an example of how to deliver design information directly to the fabrication team with few or no traditional design drawings.

A hybrid approach was adopted where most of the key design information was communicated by way of the Tekla steelwork model, but some elements were provided by way of a traditional steelwork drawing. This showed precamber, weld details and some elements of the geometry.

Although it does not eliminate two-dimensional drawings completely, the process does represent a significant step forward in the delivery of information to the fabricator. Again, most of the information contained within the design model was reused by the fabricator and, as such, savings were made in the fabricator's programme. For relatively simple beams such as these, the fabricator was also able to provide the precamber by programming their plate-cutting machines directly, eliminating the need to adjust the model to the precambered geometry.

Similarly, by only having to produce one drawing rather than a complete steelwork package, the design team also realised benefits to the programme.

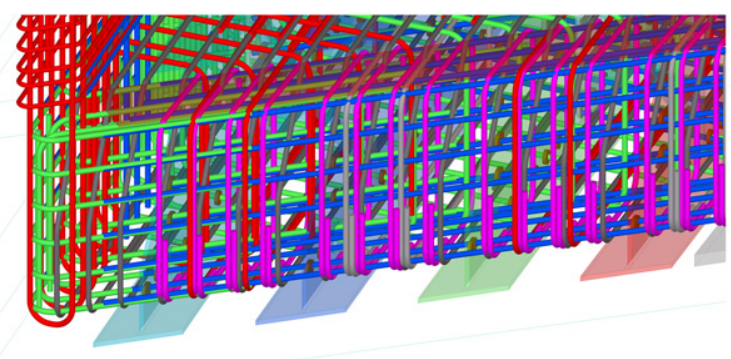

Figure 14. Image from detailed design model of Stanley Street Bridge showing both the steel beams (modelled by the fabricator) and the reinforcement (modelled by the designer)

\section{Lessons learned}

The project team set out with the aim of realising efficiencies in design and construction by challenging both the conventional roles in the design delivery process and the conventional medium of design deliverables. The expectation was that this could be achieved by working directly within the software platform, which would be used to drive the fabrication process, and by early collaboration between the design and fabrication teams.

The most successful outcomes were achieved where conventional two-dimensional design drawings were partially or entirely dispensed with, for the River Irwell Footbridge, and for the Stanley Street Bridge filler beam deck.

\subsection{Selection of software appropriate to purpose}

It was clear that there was no single software platform that could satisfy the needs of all participants in the design, construction and asset ownership life cycle.

- The asset owner and interdisciplinary design team require a single common model so they can understand and evaluate the relationship between different elements of the total railway infrastructure.

- The structural designer wishes to communicate their design intent, but does not want to fix certain aspects of construction which are best determined by the fabricator - for example plate cutting positions. The more detailed information they communicate (bolts, welds etc.) is of interest to the future asset owner, but is excessive for other discipline designers.

- The steelwork fabricator requires high geometric precision and is primarily interested in the identification of materials and assembly of components.

The project was delivered in accordance with its stated BIM requirements, with all parties receiving the information they required. However, this often introduced inefficiencies associated with the transfer of data into the formats useful to each party. Accepting these varying requirements for information, and planning the BIM requirements of future projects around them, offers opportunities to realise further efficiencies.

With hindsight, it was clear that too much structural detail was prepared within the common Microstation model, and this led to increased difficulties with data translation at later stages. In future work, only a geometric skeleton would be prepared within the common model, sufficient to confirm correct relationships to highway and railway geometry, and to define interfaces between adjacent structures. Full structural detail would be developed from the outset of a combined detailed 
design/fabrication modelling stage, and only sufficient information for interdisciplinary coordination would be brought back into the shared model. Experience on the Ordsall Chord will allow appropriate interface points and levels of detail to be better understood and defined by way of an agreed protocol.

\subsection{Design responsibility and understanding of roles}

The stated desire of using the fabricator's specialist staff to produce both the designer's model and the designer's drawings was not always successful. This method successfully delivered the design for certain structures, such as the Trinity Way Bridge, but it was often difficult for the fabricator's technicians to understand key differences in the content and presentation of design drawings compared to workshop drawings. The fabricator often wants to model and depict elements that the designer does not show, such as full plates from which smaller plates are cut (to allow plate-cutting machinery to be programmed correctly).

Over the course of the project, both designer and fabricator gained a greater appreciation of each other's requirements, which will be invaluable for future work. The designer was also able to retain clarity on their responsibility for design content, even where a combined team was responsible for preparing the design documentation.

Working directly with the fabricator's steelwork modellers gave the designer a much greater understanding of buildability issues, and allowed key areas of geometric complexity to be resolved early. A small number of contractor's requests for information were received relative to other comparable projects. The fabricator was able to plan their work and commence ordering of steel plate much earlier than would normally be the case, helping to meet tight programme deadlines. There were clear and real cost savings in producing the design deliverables, and fewer opportunities for contradictory or erroneous information to be provided.

\subsection{Software interoperability}

Exchange of data between multiple software packages was not always straightforward, and in some cases there was potential for the inadvertent introduction of error (see Section 3.4).

For the most complex element, the pair of non-structural steelwork pieces dubbed the 'cascades', which sit between the River Irwell and Trinity Way bridges, five separate software packages were involved in developing and communicating geometry and undertaking structural analysis (Microstation, Rhino, Autocad, Lusas and Tekla). This proved relatively successful.
In other instances, there were significant problems relating to the way different packages modelled curvature, and to how the IFC file exchange format represented steelwork objects. It was apparent that a detailed understanding of these issues was essential, and this understanding coalesced gradually as the project progressed.

For future work, it is likely there will remain unpredictable interoperability issues wherever data must be translated or exchanged, and these should be addressed through the use of early trials. There is no substitute for undertaking early modelling of complex areas, and testing out data conversion. As discussed in Section 2, one-way data transfer cannot be relied upon in itself. It is essential that data transfer should be verified wherever possible by transfer and reverse transfer to allow close comparison against the original source information.

\subsection{Software capability}

The initial aspiration was to create a single common steelwork model shared by the designer and fabricator. As noted above, this was not entirely possible, as the fabricator was interested in issues of plate build-up and assembly that the designer would not normally wish to show on their drawings. However, the single biggest issue was in the documentation of precamber.

The designer always wishes to work with the 'as-built' geometry of the bridge, and this is also what the future asset owner wants to see. However, the fabricator needs to incorporate precamber, and possibly other geometrical pre-sets such as allowance for weld distortion.

With the software currently available, geometric transformation of the model could not be automated, and there was a degree of wastage involved in having to rebuild model geometry to allow for precamber, as well as the possibility of error in operating from two parallel models.

The design team has had discussions with the software suppliers as to how this could be addressed in the future.

\subsection{Integration with structural software}

The project's experience with BIM was generally positive in developing and communicating the design, and integration with steelwork construction. However, limited advantage was taken of integration with structural analysis software. One-way transfer of data to generate finite-element models was used on a number of occasions, but the software platforms adopted allowed little in the way of bidirectional data transfer or exchange of intelligent information. 
This is a particular area where the software providers need to considerably enhance what they provide to allow further gains in design efficiency to be achieved.

\subsection{Compliance as opposed to innovation}

The desire to innovate in the use of BIM created a tension against the need to remain compliant with mandatory project BIM requirements. As discussed above, the software arrangements which permitted the greatest efficiencies in single-discipline design and construction were not the same as those which best facilitated multi-disciplinary design integration and future asset management.

The willingness of the alliance team to find a path through these conflicting aims was clear. On other schemes, it will be necessary to consider the correct balance between different needs. BIM standards should leave sufficient flexibility so that opportunities for innovative processes can be considered, both in terms of expected outputs and any risks involved.

\subsection{Contractual arrangements}

Two key innovations have been described in this paper: first, adopting flexibility in the traditional roles in the design and construction process, such as allowing the steelwork fabricator to help the designer prepare the design documentation; and second, dispensing with traditional deliverables such as steelwork drawings. Are these approaches reliant on collaborative forms of contract such as 'alliancing', and do they rely on early contractor and subcontractor involvement?

In the absence of the end-user of the design information, in this case the steelwork fabricator, it seems unlikely that the designer can prepare a model in a format and manner that is guaranteed to be 'ready to use'. However, with an increased general understanding of the end-user's methodologies and requirements, it should still be possible to make efficiencies in preparing the design information, particularly by eliminating many of the drawings which are currently considered necessary.

Involvement of the fabricator's modelling technicians is extremely helpful, but may not be essential. The design teams have in-house capability in using Tekla Structures, and hope to learn from this project to ensure their technicians understand how to produce models in a way that will assist the fabricator rather than simply documenting the design intent.

On the Ordsall Chord, the key enabler of efficiencies was the collaborative behaviour displayed by the various parties, combined with the willingness to challenge normal ways of working. In an 'alliancing' arrangement, the contracted scope can readily be rewritten to support the agreed delivery process.

The teams involved in this project all reported very positively on their experience, and expressed a desire to operate in a similar manner again in the future. It is the intention of the design team to try out similar approaches on projects, irrespective of the contractual arrangements. However, it can be anticipated that only with the appointment of the steelwork subcontractor can the end-to-end software platforms be confirmed and a project-specific working method agreed. Otherwise, there is the risk that efficiencies achieved in working methods and reduced design outputs may be offset by inefficiencies created by interoperability issues.

\subsection{Opportunities to adapt processes to other materials and construction types}

The methods of working adopted on the Ordsall Chord lend themselves to structural steelwork. The end-user of the design information already uses a highly automated working method, which makes effective and direct use of the digital design model provided.

Within structural engineering, there are presently few other areas of work where the same degree of automation is involved. Concrete formwork is typically assembled manually, reinforcement is fixed manually, and concrete is generally poured and compacted by manual labour.

Elsewhere in civil engineering, greater automation is being introduced, with computer-guided earthworks and tunnelling plant being examples. These are therefore areas where there are opportunities to eliminate redundant design outputs, and for the designer to better understand what format of design data can be used to drive construction work.

On the Ordsall Chord, the majority of the reinforced concrete work, both precast and cast in situ, was modelled in full three dimensions, including all reinforcement. This again used a combination of Aecosim and Tekla software, and was particularly effective for structures with complex geometry, and a close relationship with embedded steelwork models (as on the filler-beam decks). The outputs were, however, traditional, with conventional concrete outlines, reinforcement drawings and bar schedules being produced in all cases (Duguid, 2015; Duguid et al., 2017b).

Some concrete contractors are beginning to better exploit the capabilities of the latest BIM software platforms. Although the opportunities to automate are fewer than with steelwork, it appears that progress can be made where the full supply chain is engaged early, and where the parties involved are willing to collaborate closely and challenge the norm. 


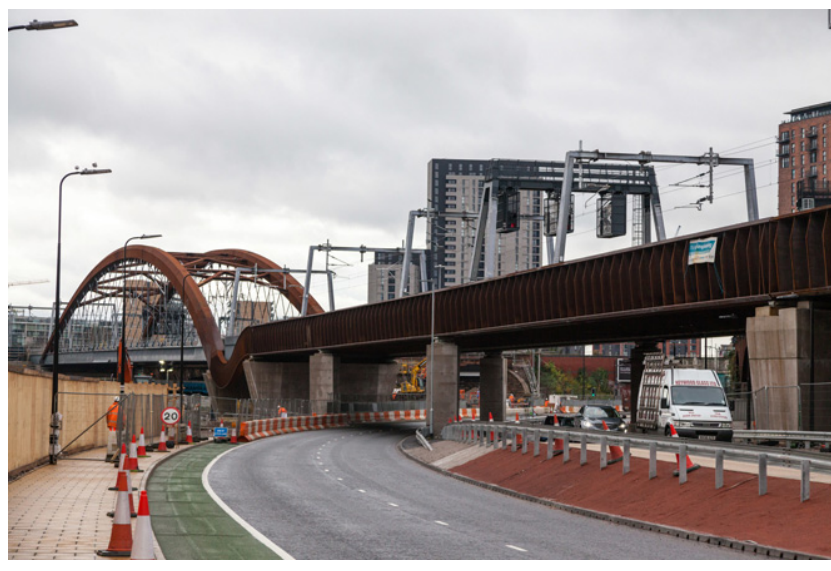

Figure 15. Completed Ordsall Chord, Manchester; image () Matthew Nichol Photography

\section{Conclusion}

The Ordsall Chord is a highly complex multidisciplinary engineering project. Many aspects of the civil engineering have been challenging to deliver, including a number of bridges that are structurally complex or geometrically complex, or both. The civil engineering design was successfully delivered using level 2 BIM and is compliant with BS 1192 (see Figure 15).

Working in a collaborative manner within an alliance structure, and with the steelwork subcontractor engaged early, it was possible to challenge normal methods of working. This allowed the best expertise within the overall team to be applied at the optimum stage during the design phase, and to achieve efficiencies in the provision of design data, including the simplification of design outputs.

The adoption of innovative roles included the steelwork fabricator's team creating the digital design model and associated drawings on the designer's behalf. The outputs produced were progressively challenged, resulting in one structure, the River Irwell Footbridge, being designed and built without any of the conventional steelwork arrangement drawings, with the primary deliverable being a three-dimensional steelwork model produced in a collaborative manner between the designer and the fabricator.

The process has encountered a number of hurdles, and lessons have been identified which can be applied to future projects. Having achieved a better understanding of the processes and requirements, the design team's view is that there remain further efficiencies to be gained on future work.

\section{Acknowledgements}

The authors would like to acknowledge the roles of the following parties involved in the project, namely: the owner participant, Network Rail; the non-owner participant for civil engineering, Skanska Bam JV; the steelwork subcontractor, Severfield (UK) PLC; the outline design of structures (Network Rail GRIP3), Parsons Brinckerhoff with BDP; the preliminary and detailed design of structures (Network Rail GRIP4/5), Aecom Mott MacDonald JV (engineering) with BDP and Knight Architects (architecture).

Also, the authors would like to acknowledge the work of the CAD and BIM teams from Aecom-Mott MacDonald JV, who have played a significant part in executing the BIM processes described in this paper. They would also like to acknowledge the following individuals who have read and commented on this paper: Nigel Jacques (Network Rail); Jarrod Hulme (Severfield); Jagvinder Singh, Jutinder Birdi and Chris Abdee (all of Aecom); and Andrew Jones, John Farrow and Lorna Webb (all of Mott MacDonald).

\section{REFERENCES}

Anon (2014) Great expectations. Rail Technology Magazine, April/May. See http://www.railtechnologymagazine.com/Interviews/ great-expectations (accessed 09/04/2018).

Bentley (2008) Bentley Systems, Incorporated (Aecosim Building Designer and Microstation). Bentley, Exton, PA, USA. See http://www.bentley.com/ (accessed 09/04/2018).

BIM Industry Working Group (2011) Strategy Paper for the Government Construction Client Group, March 2011. BIM Industry Working Group, London, UK. See https://www.cdbb.cam.ac.uk/Resources/ResoucePublications/ BISBIMstrategyReport.pdf (accessed 09/04/2018).

Bistolas T, Abbott T and Rusev R (2016) The Ordsall chord network arch bridge - addressing complex demands through collaboration. In Arch 2016 - Proceedings of the 8th International Conference on Arch Bridges, Wroclaw, Poland. Wroclaw University of Science and Technology, Wroclaw, Poland.

BSI (2007) BS 1192: Collaborative production of architectural, engineering and construction information - code of practice. BSI, London, UK.

Duguid B (2015) Northern hub proves BIM value. Concrete Magazine, October: pp. 52-53.

Duguid B and Whiteaker M (2017) The Ordsall chord, Manchester, UK - an overview. Proceedings of IABSE Symposium, Vancouver, Canada. International Association for Bridge and Structural Engineering (IABSE), ETH Zurich, Zurich, Switzerland, pp. 532-539.

Duguid B, Jenkins P and Osborne T (2017a) A case study in design collaboration: design development for the bridges of the Ordsall chord. Proceedings of IABSE Conference, Bath, UK. International Association for Bridge and Structural Engineering (IABSE), ETH Zurich, Zurich, Switzerland, vol. 108, pp. 194-201.

Duguid B, Hyde J and Pullan H (2017b) The Ordsall chord, Manchester, UK - digital delivery of design. Proceedings of IABSE Symposium, Vancouver, Canada. International Association for Bridge and Structural Engineering (IABSE), ETH Zurich, Zurich, Switzerland. 
HA (Highways Agency) (2012) Design Manual for Roads and Bridges HA, London, UK. See http://www.standardsforhighways.co.uk/ (accessed 09/04/2018).

Network Rail (2016) Ordsall Chord. Network Rail, London, UK. See http://www.networkrail.co.uk/north/Ordsall-chord.aspx (accessed 09/04/2018).
Stacy M and Birbeck J (2013) BIM for the northern hub ECS1 programme. The Structural Engineer 91(11): 50-57.

Wynne A (2013) Northern hub rail special: all points head north. New Civil Engineer, 9 August. See http://www.newcivilengineer. com/northern-hub-rail-special-all-points-head-north/8651851. fullarticle (accessed 09/04/2018).

\section{How can you contribute?}

To discuss this paper, please email up to 500 words to the editor at journals@ice.org.uk. Your contribution will be forwarded to the author(s) for a reply and, if considered appropriate by the editorial board, it will be published as discussion in a future issue of the journal.

Proceedings journals rely entirely on contributions from the civil engineering profession (and allied disciplines).

Information about how to submit your paper online is available at www.icevirtuallibrary.com/page/authors, where you will also find detailed author guidelines. 